\title{
Risk of Waterborne Parasitic Infection among Vegetables Producers in the City of Ouagadougou, Burkina Faso: An Attempt to Quantify Them Using the Quantitative Microbiological Risk Assessment Method
}

\author{
Noellie W. Kpoda1, Hamidatu S. Darimani², Adama Oueda1, Idrissa Ouédraogo, \\ Gustave B. Kabré ${ }^{1}$ \\ ${ }^{1}$ Department of Animal Biology and Physiology, Laboratory of Animal Biology and Ecology, Joseph Ki-Zerbo University, \\ Ouagadougou, Burkina Faso \\ ${ }^{2}$ Faculty of Engineering, Department of Agricultural Engineering, Dr. Hilla Limann Technical University, Wa, Ghana \\ Email: kpoda@yahoo.fr, hamidnid2012@gmail.com
}

How to cite this paper: Kpoda, N.W., Darimani, H.S., Oueda, A., Ouédraogo, I. and Kabré, G.B. (2022) Risk of Waterborne Parasitic Infection among Vegetables Producers in the City of Ouagadougou, Burkina Faso: An Attempt to Quantify Them Using the Quantitative Microbiological Risk Assessment Method. Agricultural Sciences, 13, 10-24.

https://doi.org/10.4236/as.2022.131002

Received: December 5, 2021

Accepted: January 15, 2022

Published: January 18, 2022

Copyright $\odot 2022$ by author(s) and Scientific Research Publishing Inc. This work is licensed under the Creative Commons Attribution International License (CC BY 4.0).

http://creativecommons.org/licenses/by/4.0/ (c) (i) Open Access

\begin{abstract}
The use of wastewater in urban agriculture has been promoted as an alternative to water scarcity and as a means to increase soil fertilizer. However, the use of wastewater in urban agriculture raises major public health concerns, mainly due to the often high concentration of pathogenic micro-organisms. Waterborne parasites are a major health concern in this regard, especially in endemic areas, mainly due to the high environmental resistance of eggs/cysts combined with a low infectious dose. In this study, the parasitological risk to vegetables producers in Ouagadougou using polluted water was evaluated through the quantitative microbiological risk analysis method. For this purpose, the search for and quantification of viable parasite eggs and cysts in irrigation water was coupled with epidemiological surveillance of vegetables producers in Ouagadougou. Protozoa and helminths belonging to 9 species were recorded and samples analyzed. These include Ancylostoma sp., Ascaris lumbricoides, tapeworm's sp, Strongyloides stercoralis, Entamoeba histolytica, Giardia lamblia. Despite the variability of isolated parasitic species, Ancylostoma sp. eggs were common and severe to all types of water. Moreover, epidemiological approach showed that there were more parasitic species found in irrigation water and also other parasitic species circulating among vegetable farmers. In addition, there is no statistical significant association between the type of water used for irrigation and the carried parasites by veg-
\end{abstract}


etable gardeners. However, contamination of the groups using the raw wastewater is once higher than those using well water. When one is interested in the groups using treated wastewater as a source of irrigation, these risks of contaminations are halved. These contaminations are halved when one looks at groups using treated wastewater as a source of irrigation water. Still, whatever the type of water used by the gardeners, they have a probability of infection with Ancylostoma sp. of around $9.83 \times 10^{-1}$ pppy.

\section{Keywords}

Urban Agriculture, Polluted Water, Parasites, Health Risk, Quantitative Microbiological Risk Assessment, Burkina Faso

\section{Introduction}

Biological agents encompass an enormous variety of micro-organisms, toxins and allergens that may harm human health, including those that cause infectious disease. Workers in many lines of work may be exposed to infectious agents, putting them at risk of disease [1]. Exposure can occur in different ways, such as through the intentional use of specific microorganisms' laboratories, biotechnological industries [2] [3] or through more less accidental co-exposures resulting from processes which involve many different microorganisms (composting, recycling, wastewater recycling) [4] [5] [6].

The use of wastewater to produce food crops particularly vegetables is very prevalent in Ouagadougou, Burkina Faso. There is an increase in the use of diluted or raw wastewater for farming which is mostly not the farmers' choice; usually, alternative sources of water for farming are lacking [7]. Irrigated farming of high value crops is livelihood to many urban residents of the city since it provides employment and income [8]. About $60 \%$ of the city's vegetable consumption, particularly leafy vegetable, is supplied by urban farmers who irrigate their crops using polluted river water or diluted wastewater [7] [9] [10]. However, several studies also report high levels of pathogen indicator organisms and heavy metals in polluted urban water sources [11] [12] [13].

However, throughout the past decade, much research has been directed towards identifying the occurrence, epidemiology, and risks associated with waterborne protozoa and helminths. While outbreaks are continually documented, sporadic cases of disease associated with exposure to low levels of waterborne protozoa and helminths are of increasing concern [14] [15] [16] [17]. Current methodologies may not be sensitive enough to detect these low levels of disease

[17]. However, risk assessment methods may be utilised to address these low-level contamination events [11]. The purpose of this article is to provide an introduction to microbial quantitative risk assessment for waterborne protozoa and helminths by using specific groups of vegetable producers using polluted water in 
urban gardens.

\section{Methodology}

\subsection{Study Area}

The study was carried out in on the area called "Grand Ouaga" which is located between latitudes $12.05^{\circ}$ to $12.68^{\circ}$ and longitudes $1.83^{\circ}$ to $1.04^{\circ}$. "Grand Ouaga" is an administrative zone which includes the urban commune of Ouagadougou and seven rural communes surrounding Ouagadougou. The population increased from 649,373 in 1985 to 2,532,311 in 2015, of which 83\% is classified as urban. The city lies within the Sudanese savannah type climate zone, where seasons are controlled by the movement of the Intertropical Convergence Zone. Ouagadougou is characterized by two main seasons: a dry season from October to April and a rainy season from May to September. The peak rainfall generally recorded in August. The mean annual rainfall was $770 \mathrm{~mm} /$ year during the period 1961-2015 [18]. Temperatures vary from a daily minimum of $16^{\circ} \mathrm{C}$ in December to a daily maximum of $40^{\circ} \mathrm{C}$ in March and April.

The landscape is dominated by gently undulating plains with elevations ranging from 237 to $355 \mathrm{~m}$. In the city there are many shallows and intermittent tributaries. The Massili river passes through Ouagadougou by means of three dams, namely Ouaga I, II, and III, and discharges into the Nakanbe River [18]. These dams constitute the catchment area for rainwater and contribute to the city's drinking water supply. A fourth dam is located in the western part of the city. The water from these reservoirs is used for urban agriculture. Thus, Somé et al. [19] identified 24 places in the city, which spread over 14 sectors, as market gardening sites in the dry season with 5310 market gardeners.

The major production site based on the source of water used for irrigation was selected for risk assessment. The Boulmiougou market garden perimeter, around the dam located on the western side of the town was selected. The perimeter extends over approximately 60 hectares and is exploited by more than 500 market gardeners. They use untreated natural water from wells and dam reservoir. The Wayalghin market garden site has been developed in the marshy areas along the Wemtenga sewage drainage channel to the east of the town. It is an undeveloped low-lying area operated by 125 growers who take wastewater directly from the drainage channel to water their crops. The Kossodo market garden site has been designed to reuse the treated wastewater situated at $50 \mathrm{~m}$ downstream of the lagoon-based wastewater treatment plant (WWTP). The WWTP of Ouagadougou was built in 2004 to receive domestic wastewater from hotels, the downtown area, hospitals, pre-treated (settled) industrial wastewater from a slaughterhouse and a brewery. At the time of the study this site was occupied by about 30 market gardeners (mainly women).

\subsection{Water Quality}

A water quality survey was conducted at the study sites using water sources used 
for crop irrigation, which showed typical properties of domestic wastewater with relatively high concentrations of Escherichia coli and hookworms [7] [19]. Water quality improves significantly depending on the source of water used. Indeed, in positive water samples, the eggs average densities were 16.94 and $11.77 \mathrm{egg} / \mathrm{L}$ respectively in untreated natural water (well water) and treated wastewater and $55.88 \%$ of these hookworm eggs were found to be viable [7]. This finding led to the hypothesis that, depending on the nature of the irrigation water, the prevalence of hookworms among farmers occupationally exposed to water used in urban agriculture in Ouagadougou could vary from one site to another.

\subsection{Study Population}

To test the hypothesis a cross-sectional descriptive survey of a sample of market gardeners from the sites selected for the study was conducted from February 19 to March 5, 2014. The size of the sample was determined by the desire to have a statistically significant sample size. Thus, considering the work of Cissé [20] who estimated the prevalence of intestinal helminthic infection at $40.6 \% \pm 7.36 \%$ in the population of market gardeners in Ouagadougou, a theoretical number of 235 individuals were set for this study. Inclusion criteria were to have market garden production as main activity and should be operating on the same site for more than two agricultural seasons. In the end, 203 market gardeners who gave their consent were enrolled in this study.

\subsection{Data Collection}

A cross-sectional survey was conducted among the selected market gardeners using a questionnaire. The extent of contact with polluted water was assessed for all individuals on individual information separate from the sheets. It included the status of any contact with polluted waters, and in the case of contact, the type of contact (seasonal or year-round), the average frequency of contact (days per month) and the quantity ingested (if any). Other information collected for each individual was age, sex, occupation, educational status, types of agricultural production involved and use of protective measures during agricultural work.

\subsection{Stool Sample Collection and Enumeration of Parasites Eggs and Cysts}

The purpose of this survey was to establish the prevalence of parasitic infections in the market garden population surveyed and to identify the parasite species to be considered for risk characterization. These vials were labeled with study ID numbers corresponding to those recorded in the individual information sheets were given to each market gardener after the interview and recovered the next day with stool samples taken the same morning. In order to avoid false negatives, each grower provided stool samples on two consecutive days.

The samples thus collected were brought back to the laboratory and analyzed immediately by direct macroscopic and microscopic examination and after con- 
centration according to Bailenger's standard two-phase method. Subjects were defined as having intestinal parasitosis when examination of the faeces revealed the presence of at least one species of intestinal parasite, whether eggs or adult larvae in the case of helminths or vegetative and/or cystic forms in the case of protozoa. For samples that were positive for one or more helminth and/or protozoa types, egg counts were expressed as eggs per gram of faeces (EPG).

\subsection{Ethical Aspects}

People participated in the study after informed consent. Ethical clearance for the study was provided by the National Ethics Committee of Burkina Faso. All individuals with a positive stool sample for intestinal nematodes were informed after the examination and provided with adequate anti-helminth treatment free of charge.

\subsection{Data Analysis}

The results were grouped by seasons for the analysis. Continuous and binary data were obtained. According to the Shapiro-Wilk test, continuous data were not normally distributed. Therefore, the non-parametric Kruskal-Wallis test was used to look for relationships between the parameters measured at the sampling sites. In addition, linear correlation analyses were performed to identify the relationship between the measured parameters. A significance level of $p<0.05$ was selected. The parameters obtained in this study were then compared to the standards established by the World Health Organization and the Food and Agriculture Organization for non-restrictive irrigation to determine the level of safety of irrigation water in Ouagadougou.

For the risk assessment, Quantitative Microbiological Risk Assessment (QMRA) was used. The QMRA has been conducted as described by Haas [21]. This method follows a four main step process consisting in: 1) hazard identification, 2), 3) dose-response modelling and 4) risk characterization.

\subsubsection{Hazard Identification}

To predict the health risk in this study, we chose to analyze Ancylostoma duodenale, which is the main species of intestinal parasite to which the urban farmer in Ouagadougou is exposed.

\subsubsection{Exposure Assessment}

The aim of the exposure assessment in this QMRA was to estimate the concentrations and doses of Ancylostoma duodenale to which the affected population might be exposed to. Key parameters measured for the exposure assessment was Ancylostoma duodenale concentrations in irrigation water. So, the concentration of parasites has been measured by the Bailenger method adapted to the quantification of parasites in wastewater by Bouhoum and Schwartzbrod [22]. Levels of microbiological contamination are often strongly associated with the expected risk. However, these pathogen concentration data are often affected by 
factors such as the low number of parasites present in a water sample relative to the limit of detection (LOD) or limit of quantification (LOQ) of the analytical method. In addition, non-detection poses a difficulty when it is necessary to calculate statistical measures such as mean, median and standard deviation for a data set. Consequently, a maximum likelihood approach as described by CullenFrey [23], Efron and Tibshirani [24] by was adopted. Then, we used the "mc2d" package of $\mathrm{R}$ as recommended by Pouillot and Delignette-Muller [25] to account for uncertainties and variability in parasite concentrations in water samples. The volume of water ingested by market gardeners during each exposure was estimated from the literature [21]. It is well known that the distribution and concentration of parasites in water is highly variable [26].

One scenario was used in the exposure assessment for this study. It concerned wastewater ingested during urban farming activities, and described the exposure dynamics when practicing urban farming activities using water of poor quality at Ouagadougou. For this scenario, activity frequencies, duration and type of protection were investigated by using a questionnaire.

\subsubsection{Dose-Response Assessment}

Dose-response assessment examines the incidence of infection or disease as a health outcome in the exposed population. In this study, the focus was on the human-to-human pathway of transmission, but exclusively on pathways involving the environment. Moreover, this dynamic conceptual approach is population-based and the risk of infection is manifested at the population level. In the case of parasitosis, which is an infectious disease, the risk of disease due to exposure to pathogens depends on the health status of the population and possibly on the modalities of contact. Therefore, for the purposes of this study, we will assume that our population is immunologically homogeneous.

Furthermore, it is known that the infection of an individual by a parasite is a function of the exposure dose. The determination of this dose involves dose-response relationships. Two dose-response models are widely used in the literature. These are the Exponential and Beta-fish models, as they correspond well to the behavior of several microorganisms [21]. In addition, the Beta-Fish model takes into account the variations that exist in pathogen-host interactions. The parameters of this model were calculated using the Maximum Likelihood Method (MLM). A dose-response model is acceptable when the parameter values, Ymin, minimize deviance by Haas et al. [21], the beta-fish model developed by Navarro et al. [27], meets this criterion. Moreover, our data follow a Beta-fish distribution. The probability of infection was therefore calculated according to the equation of the beta-fish model:

$$
P_{\text {inf }}=1-\left(1+\left(d / N_{50}\right)\left(2^{1 / \alpha}-1\right)\right)^{-\alpha}
$$

where

$P_{\text {inf }}$ is the probability of infection, 
$r$ is the probability that a single parasite can cause disease in the infected host,

$d$ is the ingested dose,

$N_{50}$ is the infectious dose for $50 \%$ of the population and,

$\alpha$ is a slope parameter.

A QMRA for each pathogen that can be transmitted through water would be tedious and the necessary information is currently unavailable for many pathogens. To overcome this difficulty, WHO [28] recommended the use of a of "reference pathogens". A reference pathogen is an organism whose severity of impact and persistence in water is such that its control would provide assurance that health risks from pathogens of a similar nature have also been controlled [28]. Ankylostoma spp has characteristics similar to those of Ascaris sp, which is a 'reference pathogen. For this reason, in this study, we assume that the $N_{50}=35$ and $\alpha=0.104$ values for Ascaris sp. applicable to Hookworm.

The above $P_{\text {inf }}$ infection probability is the probability of infection for a single exposure. Annual risk of infection was calculated as follows:

$$
P_{\text {inf }}(A)=1-\left(1-P_{\text {inf }}\right) n
$$

where $P_{\text {inf }}(A)$ is the probability of infection per person per year (pppy).

\subsubsection{Risk Characterization}

Risk characterization integrates the information from the previous three steps into a simple mathematical model to calculate risk as a probability of infection, illness or death. In our study, we calculated the risk of infection. The risk was calculated using a stochastic approach, with inputs being probability density functions (PDFs) of each parameter if the data were available and plausible for PDF editing and simulation under $\mathrm{R}$. The calculation showed that the parasite concentrations in the different replicates corresponded best to a Beta fish law. The simulation yielded a range of possible risks, including mean and worst-case scenarios. The model output was run with the simulation of $\mathrm{R}$ at 1001 permutations.

\section{Results}

\subsection{Exposed Population Characteristics}

The majority of farmers had no formal education (80.0\%), and were all above 21 years of age with an average age of $44 \pm 12$ years. Among the farmers, 53\% were males and $47 \%$ were females. They live mostly $(85 \% \pm 4 \%)$ in a relationship with 4 children. Almost half of the people surveyed have more than 10 years of experience in urban farming and own plots with an average size of $188.6 \pm 12.6 \mathrm{~m}^{2}$.

\subsection{Exposure Patterns in the Study Area}

The majority of the study population uses well water to water their crops. Indeed, $50.2 \%$ of the market gardeners interviewed responded that they use well water (46.3\% in Boulmiougou vs. $4 \%$ in Wayalgin), followed by $39.8 \%$ who said 
they use wastewater from stormwater drainage channels as a source of irrigation. The remaining $10 \%$ use treated wastewater from the city's only wastewater treatment plant. The observed differences in the sources of irrigation water for vegetable crops are statistically significant $(p<0.005)$.

More than half of the study population spends between 11 and 12 hours $(55.2 \%$ $\pm 28 \%$ ) on market gardening sites. Most of them are mainly on the Boulmiougou site $(39.8 \% \pm 28 \%, p<0.005)$. During all this time spent on the sites, the market gardeners eat, drink and did their natural needs. In fact, $98 \%$ reported eating on the site and $90.5 \%$ of this food comes from the street. In addition, $55.3 \% \pm 6 \%$ reported taking their drinking water from home to the site. However, the market gardeners in Boulmiougou use more irrigation water as drinking water than those in the other site $(30.5 \% \pm 6 \%$ vs. $1.5 \% \pm 6 \%$ in Wayalgin, $p<0.005)$. They drink an average of $3 \mathrm{~L}$ of this water per day. Before eating, more than half of the market gardeners reported washing their hands with sprinkler water. In addition, the majority of market gardeners interviewed in this survey do not observe personal protective measures when conducting their activities. Indeed, 98.5\% \pm $2 \%$ to $100 \%(p=0.66)$ of the market gardeners do not use Personal Protective Equipment (PPE) either during watering or during the application of agricultural inputs invariably from the site. In addition, $99 \%$ of them wash their feet and hands only with water after these activities. In terms of satisfying their natural needs on the site, the market gardeners proceed according to one of the following three modalities: defecation in the woods surrounding the site, defecation in abandoned market garden wells on site and finally in the toilets at home or at the homes of friends near to the site in proportions that are $67 \% \pm 4 \%, 29.9 \% \pm$ $4 \%$ and $3 \% \pm 4 \%$ respectively $(p=0.0001)$.

\subsection{Parasitological Status of the Farmers Surveyed}

A total of 195 farmers actually gave stool samples for analysis. A proportion of $57.9 \% \pm 2 \%\left(\mathrm{X}^{2}=2.22, p=0.33\right)$ carried at least one of the following parasitic species: Entamoeba coli, Entamoeba histolytica, Giardia lamblia, Trichuris trichura, Hymenolepis nana, Ancylostoma duodenale, Stronglyloid stercoralis, Trichomonas intestinalis, and Taenias sp. The overall prevalence for these parasites was $62 \% \pm 16 \%$ for Entamoeba coli, $40 \% \pm 16 \%$ for Entamoeba histolytica, $10 \% \pm 16 \%$ for Ankylostom sp. Market gardeners at the Kossodo site had an overall prevalence of parasitic infections that was $70 \%$ higher than at the Boulmiougou (60\%) and Wayalgin (53\%) sites, but not significantly so $\left(\mathrm{X}^{2}=2.22 \mathrm{df}=\right.$ $2, p=0.33$ ). The distribution of parasitic species encountered is shown below. Furthermore, there was no statistically significant association between the type of water used for irrigation and the carrying of parasites by the vegetable growers. However, the chances of contamination of the groups using raw sewage water were more than one times higher than those using well water (odds ratio, $\mathrm{OR}=$ 1.33 at $95 \%$; confidence interval, $\mathrm{CI}=0.70-2.54 ; p=0.36$ ).

Risk of Ancylostoma duodenal infection in exposed vegetable farmers. The 
concentrations of Ancylostoma duodenale were fitted via standard distributions. Figure 1 and Figure 2 show the best fitting probability distribution functions and corresponding parameter bootstrap for Ancylostoma duodenale. The graphical analysis shows that the Beta-poisson distribution provides the best fit to the Ancylostoma duodenale concentration dataset in irrigation water.

\subsection{Risk of Ancylostoma duodenale Infection in Vegetable Farmers Associated with Exposure to Irrigation Water}

The average risk of infection for a vegetable farmer associated with a single

\section{Cullen and Frey graph}

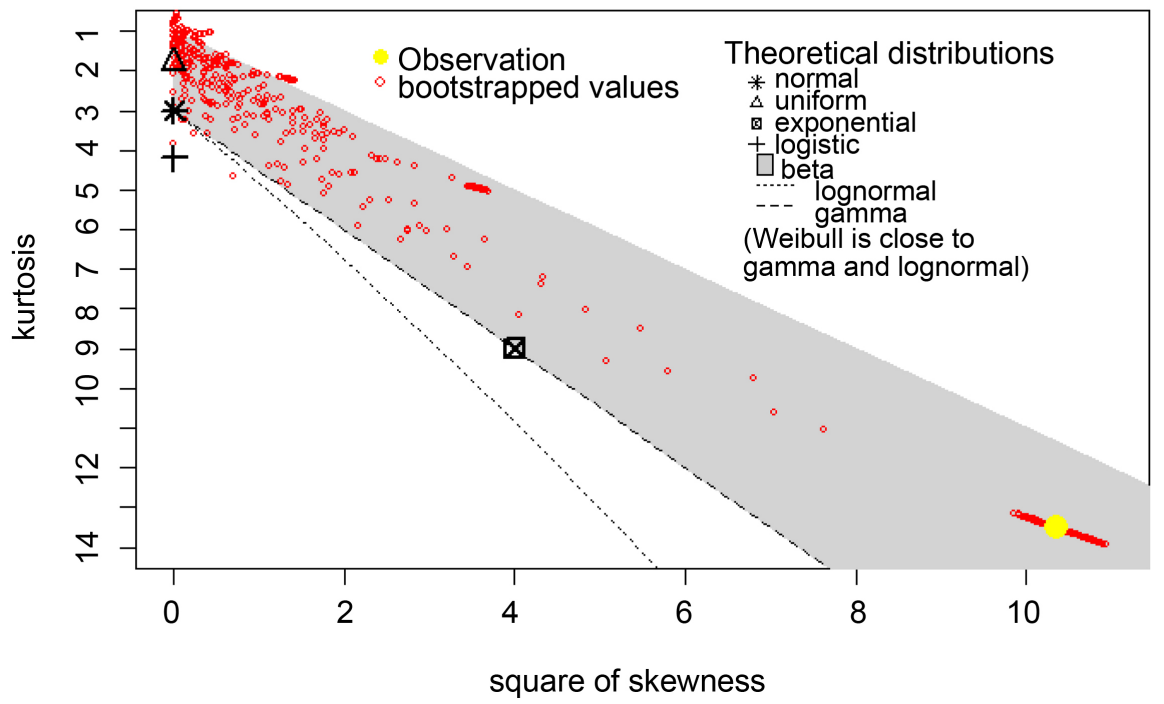

Figure 1. Output of R's descdist function: skewness-kurtosis graph for Ancylostoma duodenale concentration in irrigation water.
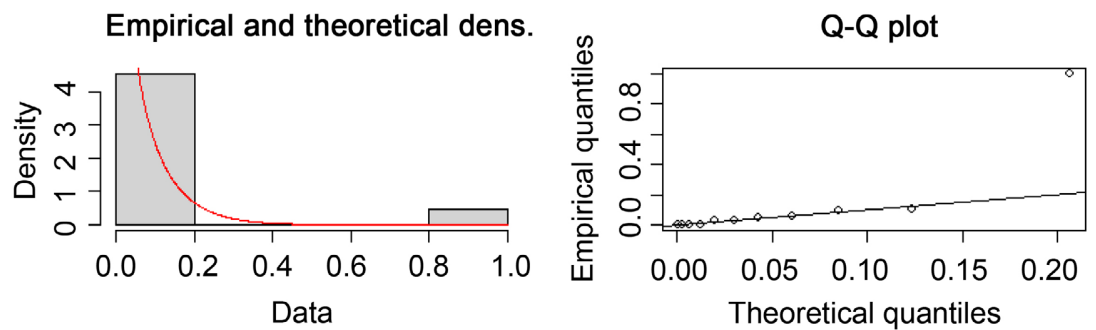

Empirical and theoretical CDFs
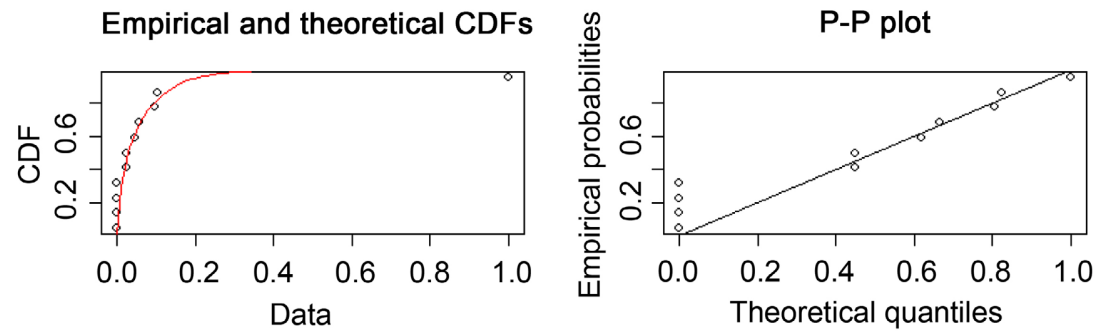

Figure 2. Results of fitting a beta-fish distribution to the concentration of Ancylostoma duodenale in the irrigation water. 
exposure to polluted irrigation water was $2.69 \times 10^{-1}$ (95\% CI 0.19 to 0.34$)$ pppy (Figure 3). The cumulative mean annual risk of infection with Ankylostoma sp. for vegetable farmers in Ouagadougou was $9.83 \times 10^{-1}$ pppy (95\% CI 0.92 to 1.00) (Figure 4).

\section{Discussion}

Urban market gardening, irrigation with polluted water in semi-arid areas is a widespread and growing phenomenon with different degrees of risk [29] [30]. Kpoda et al. [12] showed that low-quality irrigation water was use for vegetables production in Ouagadougou city. Indeed, as in neighbouring Ghanaian cities as reported by Owusu et al. [31]. They indicated that $39.8 \%$ of the market gardeners surveyed responded they used wastewater from rainwater drainage channels as a source of irrigation. According to Blumenthal et al., [32], Jimenz [33] and

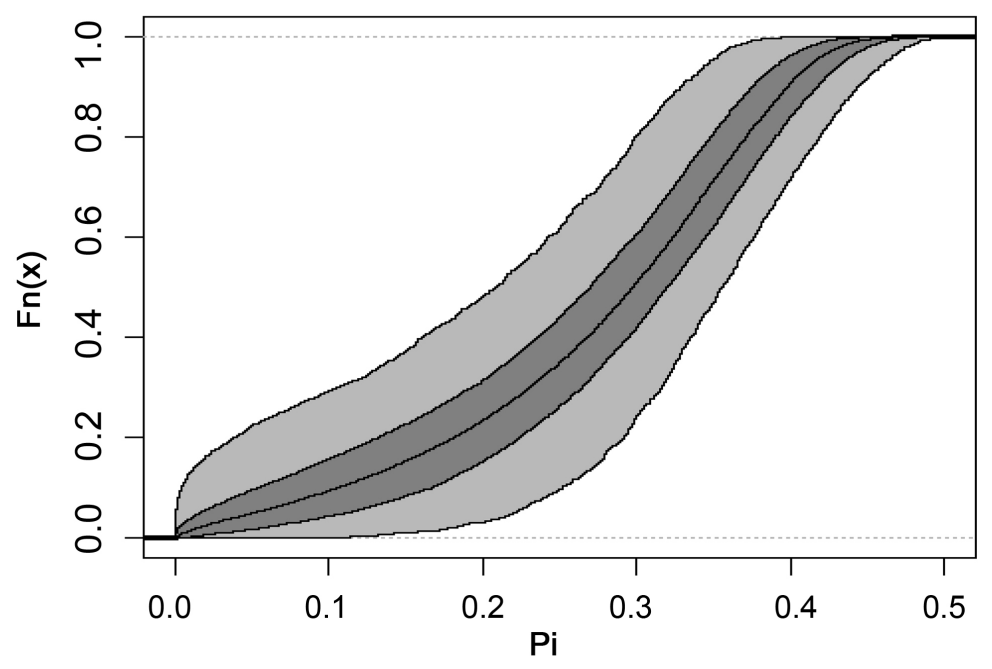

Figure 3. Cumulative probability distribution of the risk of Ancylostoma duodenale infection associated with irrigation water exposure.

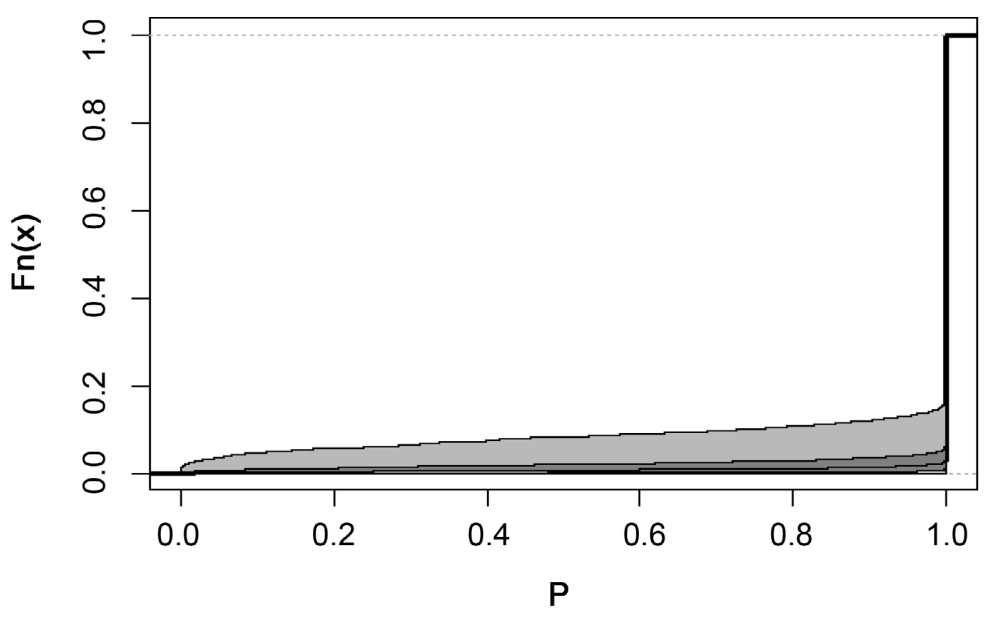

Figure 4. Cumulative probability distribution of the risk of Ancylostoma duodenale infection associated with annual exposure to irrigation water. 
Pham-Duc et al. [34] the major risk in developing countries such as Burkina Faso linked to irrigation with low quality water is enteric parasite infections. This could be explained on the one hand by the lack of appropriate sanitation facilities and drainage infrastructure as in most cities of Sub-Sahara Africa [35] [36]. The lack of sanitation has direct causes of water pollution, and on the other hand by the behaviour and practices of the market gardeners themselves at their workplaces. Indeed, several market gardeners interviewed stated that they drink an average of 3 liters of water that does not meet WHO standards for irrigation, let alone potability standards. In addition, most of these market gardeners spend the day on the site, in contact with this irrigation water, containing viable parasite eggs (therefore likely to continue their development cycle) without protective equipment. These behaviours are likely to favor the installation and spread of parasitic infections within the population. It is acknowledged that host competence to transmit parasites is not solely the product of the immune system, but is also simultaneously determined through behaviors that limit contact with parasites, vectors, or other hosts [37] [38]. Therefore, in order to prevent and control these infectious diseases, the provision of basic sanitation facilities, combined with education and promotion of hygiene and personal protection practices in the workplace is necessary.

Moreover, the epidemiological data collected during this study shows that there is a real risk of infection by intestinal parasites, which was confirmed by the prevalence rate of over $50 \%$ observed in our study population. The parasitic species of greatest concern are Entamoeba histolytica and Ankylostoma sp. because of the high number of market gardeners who are carriers, and above all, because of their impact on the health of infected people. Intestinal helminthes infections causes nutritional deficiencies, which contribute most to anemia which could result from blood loss directly through ingestion and mechanical damage of the intestinal mucosa and indirectly, by affecting the supply of nutrients necessary for erythropoiesis resulting in anemia [39]. Hookworm infections are recognized as the leading cause of pathologic blood loss in tropical and subtropical countries [40]. Hookworm is considered a major threat to the health of adolescent girls and women of childbearing age, with negative effects on pregnancy outcomes [41]. Previous research reported that parasitic diseases cause more deaths worldwide that all other neglected tropical diseases combined [42]. The study population is predominantly made up of this category of women, knowing that they are at an annular risk of $9.83 \times 10^{-1}$ pppy, health authorities should take measures to protect and contain these foci of intestinal helminthes infection spread in the general population.

Furthermore, the treatment of wastewater in lagoon-based treatment plants, consisting of a succession of ponds, has long been considered the ultimate solution for the reduction of parasitic infections related to the use of polluted water in agriculture [43]. The results of the investigations on the parasitological status of our market gardeners corroborate this assertion. Indeed, even without being 
statistically different, wastewater treatment would halve the chances of parasite contamination of the group using treated wastewater compared to those using raw wastewater. However, monitoring of effluent quality at these plants across Africa has shown that effective wastewater treatment does not guarantee good quality treated wastewater to the field. Despite the effectiveness of the treatment, this treated wastewater is subject to faecal recontamination at the market garden site [12] [44]. Therefore, to reuse treated wastewater and avoid new contamination, a safety plant is necessary.

\section{Conclusion}

The study had two main limitations. First, due to its cross-sectional design, this study only reflects one point in time, i.e., the dry season, and thus, we may underestimate seasonal patterns of intestinal parasite infections. Due to the relatively low number of workers included, the observed or between intestinal parasitic infection and exposure variables for workers have to be interpreted with caution. Despite these limitations, our findings raise a number of important issues. This study highlights the exposure routes and the risks of infection with waterborne diseases linked to the poor water quality used for farming activities in the context of water scarcity and food security. Facing this dilemma, farmers have to be sensitized about the potential occupational health threat when using lake waters and wastewaters from drainage networks during urban agricultural practices in Ouagadougou. Innovative water treatment infrastructures have to be implemented in order to treat wastewater pollutants before agricultural use and to optimize the current public health situation.

\section{Conflicts of Interest}

The authors declare no conflicts of interest regarding the publication of this paper.

\section{References}

[1] Haagsma, J.A., Tariq, L., Heederik, D.J. and Havelaar, A.H. (2012) Infectious Disease Risks Associated with Occupational Exposure: A Systematic Review of the Literature. Occupational and Environmental Medicine, 69, 140-146. https://doi.org/10.1136/oemed-2011-100068

[2] Weinstein, R.A. and Singh, K. (2009) Laboratory-Acquired Infections. Clinical Infectious Diseases, 49, 142-147. https://doi.org/10.1086/599104

[3] Coelho, A.C. and García Díez, J. (2015) Biological Risks and Laboratory-Acquired Infections: A Reality That Cannot Be Ignored in Health Biotechnology. Frontiers in Bioengineering and Biotechnology, 3, Article No. 56. https://doi.org/10.3389/fbioe.2015.00056

[4] Fuhrimann, S., Winkler, M.S., Kabatereine, N.B., Tukahebwa, E.M., Halage, A.A., Rutebemberwa, E., Medlicott, K., Schindler, C., Utzinger, J. and Cissé, G. (2016) Risk of Intestinal Parasitic Infections in People with Different Exposures to Wastewater and Fecal Sludge in Kampala, Uganda: A Cross-Sectional Study. PLoS Neg- 
lected Tropical Diseases, 10, e0004469. https://doi.org/10.1371/journal.pntd.0004469

[5] Fuhrimann, S., Nauta, M., Pham-Duc, P., Tram, N.T., Nguyen-Viet, H., Utzinger, J., Cissé, G. and Winkler, M.S. (2017) Disease Burden Due to Gastrointestinal Infections among People Living Along the Major Wastewater System in Hanoi, Vietnam. Advances in Water Resources, 108, 439-449. https://doi.org/10.1016/j.advwatres.2016.12.010

[6] Woldetsadik, D., Drechsel, P., Keraita, B., Itanna, F. and Gebrekidan, H. (2018) Farmers' Perceptions on Irrigation Water Contamination, Health Risks and Risk Management Measures in Prominent Wastewater-Irrigated Vegetable Farming Sites of Addis Ababa, Ethiopia. Environment Systems and Decisions, 38, 52-64. https://doi.org/10.1007/s10669-017-9665-2

[7] Kpoda, N.W., Oueda, A., Somé, Y.S.C., Cissé, G., Maïga, A.H. and Kabré, G.B. (2015) Physicochemical and Parasitological Quality of Vegetables Irrigation Water in Ouagadougou City, Burkina-Faso. African Journal of Microbiology Research, 9, 307-317. https://doi.org/10.5897/AJMR2014.7295

[8] Bellwood-Howard, I., Häring, V., Karg, H., Roessler, R., Schlesinger, J. and Shakya, M. (2015) Characteristics of Urban and Peri-Urban Agriculture in West Africa: Results of an Exploratory Survey Conducted in Tamale (Ghana) and Ouagadougou (Burkina Faso). International Water Management Institute (IWMI).

[9] Hilou, A., Ouedraogo, I., Sombié, P., Guenné, S., Paré, D. and Compaoré, M. (2016) Leafy Amaranthus Consumption Patterns in Ouagadougou, Burkina Faso. African Journal of Food, Agriculture, Nutrition and Development, 16, 11248-11264. https://doi.org/10.18697/ajfand.76.13810

[10] Karg, H. and Drechsel, P. (2018) Atlas of West African Urban Food Systems: Examples from Ghana and Burkina Faso. International Water Management Institute (IWMI).

[11] Mahmood, A. and Malik, R.N. (2014) Human Health Risk Assessment of Heavy Metals Via Consumption of Contaminated Vegetables Collected from Different Irrigation Sources in Lahore, Pakistan. Arabian Journal of Chemistry, 7, 91-99. https://doi.org/10.1016/j.arabjc.2013.07.002

[12] Kpoda, N.W., Dakouré, M.S., Savadogo, B., Maiga, A.H., Poda, J.N. and Kabré, G.B. (2016) Recontamination Effect of Treated Wastewater on Prevalence of Intestinal Helminthes: Case Study on Vegetable Producers Groups in Ouagadougou (Burkina Faso). Journal of Water and Environment Technology, 14, 125-134.

[13] Millogo, R., Rossier, C., Soura, A.B. and Cisse, S. (2018) Impacts Socio-Économiques des Inégalités de Genre sur la Fécondité à Ouagadougou: Éclairage à Partir des Donnees de l'observatoire de Population de Ouagadougou. African Population Studies, 32, 4428-4442. https://doi.org/10.11564/32-3-1227

[14] Slifko, T.R., Smith, H.V. and Rose, J.B. (2000) Emerging Parasite Zoonoses Associated with Water and Food. International Journal for Parasitology, 30, 1379-1393. https://doi.org/10.1016/S0020-7519(00)00128-4

[15] Mansfield, L.S. and Gajadhar, A.A. (2004) Cyclospora cayetanensis, a Food- and Waterborne Coccidian Parasite. Veterinary Parasitology, 126, 73-90. https://doi.org/10.1016/j.vetpar.2004.09.011

[16] Newell, D.G., Koopmans, M., Verhoef, L., Duizer, E., Aidara-Kane, A., Sprong, H., Opsteegh, M., Langelaar, M., Threfall, J., Scheutz, F., der Giessen, J.V. and Kruse, H. (2010) Food-Borne Diseases-The Challenges of 20years Ago Still Persist While New Ones Continue to Emerge. International Journal of Food Microbiology, 139, S3-S15. https://doi.org/10.1016/j.ijfoodmicro.2010.01.021 
[17] Tefera, T., Tysnes, K.R., Utaaker, K.S. and Robertson, L.J. (2018) Parasite Contamination of Berries: Risk, Occurrence, and Approaches for Mitigation. Food and Waterborne Parasitology, 10, 23-38. https://doi.org/10.1016/j.fawpar.2018.04.002

[18] Tazen, F., Diarra, A., Kabore, R.F.W., Ibrahim, B., Bologo/Traoré, M., Traoré, K. and Karambiri, H. (2019) Trends in Flood Events and Their Relationship to Extreme Rainfall in an Urban Area of Sahelian West Africa: The Case Study of Ouagadougou, Burkina Faso. Journal of Flood Risk Management, 12, e12507. https://doi.org/10.1111/jfr3.12507

[19] Somé, Y.S.C., Kpoda, W., Gampini, E.E. and Kabré, G.B. (2014) Microbiology and Parasitology Assessment of Irrigation Water Used for Production of Vegetables in Ouagadougou, Burkina Faso. Research \& Reviews in BioSciences, 9, 7.

[20] Cissé, G. (1997) Impact Sanitaire de l'utilisation d'eaux Polluées en Agriculture Urbaine. Cas du Maraîchage à Ouagadougou (Burkina Faso). Département de génie rural, Ecole Polytechnique Fédérale de Lausanne, Lausanne.

[21] Haas, C.N., Rose, J.B. and Gerba, C.P. (1999) Quantitative Microbial Risk Assessment. John Wiley \& Sons, Hoboken.

[22] Bouhoum, K. and Schwartzbrod, J. (1989) Quantification of Helminth Eggs in Waste Water. International Journal of Hygiene and Environmental Medicine, 188, 322-330.

[23] CullenFrey, A. (1999) Probabilistic Techniques in Exposure Assessment. Plenum Press, New York.

[24] Efron, B. and Tibshirani, R.J. (1993) An Introduction to the Bootstrap. CRC Press, New York.

[25] Pouillot, R. and Delignette-Muller, M.L. (2010) Evaluating Variability and Uncertainty Separately in Microbial Quantitative Risk Assessment Using Two R Packages. International Journal of Food Microbiology, 142, 330-340. https://doi.org/10.1016/j.ijfoodmicro.2010.07.011

[26] Howard, G., Pedley, S. and Tibatemwa, S. (2006) Quantitative Microbial Risk Assessment to Estimate Health Risks Attributable to Water Supply: Can the Technique Be Applied in Developing Countries with Limited Data? Journal of Water and Health, 4, 49-65. https://doi.org/10.2166/wh.2006.0004

[27] Navarro, I., Teunis, P., Moe, C. and Jiménez, B. (2010) Approaches to Evaluate and Develop Health Risk-Based Standards Using Available Data. IWMI Books, Reports H042604, International Water Management Institute.

[28] WHO (2004) Guidelines for Drinking-Water Quality. World Health Organization.

[29] Khalid, S., Shahid, M., et al. (2018) A Review of Environmental Contamination and Health Risk Assessment of Wastewater Use for Crop Irrigation with a Focus on Low and High-Income Countries. International Journal of Environmental Research and Public Health, 15, Article No. 895. https://doi.org/10.3390/ijerph15050895

[30] Gudda, F.O., Waigi, M.G., Odinga, E.S., et al. (2020) Antibiotic-Contaminated Wastewater Irrigated Vegetables Pose Resistance Selection Risks to the Gut Microbiome. Environmental Pollution, 264, Article ID: 114752. https://doi.org/10.1016/j.envpol.2020.114752

[31] Owusu, V., Bakang, J.E.A., Abaidoo, R.C. and Kinane, M.L. (2011) Perception on Untreated Wastewater Irrigation for Vegetable Production in Ghana. Environment, Development and Sustainability, 14, 135-150. https://doi.org/10.1007/s10668-011-9312-x

[32] Blumenthal, U.J., Mara D.D., et al. (2000) Guidelines for the Microbiological Quali- 
ty of Treated Wastewater Used in Agriculture: Recommendations for Revising WHO Guidelines. Bulletin of the World Health Organization, 78, 1104-1116.

[33] Jimenez, B. (2007) Helminth Ova Removal from Wastewater for Agriculture and Aquaculture Reuse. Water Science and Technology, 55, 485-493. https://doi.org/10.2166/wst.2007.046

[34] Pham-Duc, P., Nguyen-Viet, H., Hattendorf, J., et al. (2013) Ascaris lumbricoides and Trichuris trichiura Infections Associated with Wastewater and Human Excreta Use in Agriculture in Vietnam. Parasitology International, 62, 172-180. https://doi.org/10.1016/j.parint.2012.12.007

[35] Douglas, I. (2018) The Challenge of Urban Poverty for the Use of Green Infrastructure on Floodplains and Wetlands to Reduce Flood Impacts in Intertropical Africa. Landscape and Urban Planning, 180, 262-272.

https://doi.org/10.1016/j.landurbplan.2016.09.025

[36] Satterthwaite, D. (2017) The Impact of Urban Development on Risk in Sub-Saharan Africa's Cities with a Focus on Small and Intermediate Urban Centres. International Journal of Disaster Risk Reduction, 26, 16-23. https://doi.org/10.1016/j.ijdrr.2017.09.025

[37] Barron, D.G., Gervasi, S.S., Pruitt, J.N. and Martin, L.B. (2015) Behavioral Competence: How Host Behaviors Can Interact to Influence Parasite Transmission Risk. Current Opinion in Behavioral Sciences, 6, 35-40. https://doi.org/10.1016/j.cobeha.2015.08.002

[38] Piecyk, A., Roth, O. and Kalbe, M. (2019) Specificity of Resistance and Geographic Patterns of Virulence in a Vertebrate Host-Parasite System. BMC Evolutionary Biology, 19, Article No. 80. https://doi.org/10.1186/s12862-019-1406-3

[39] Geary, T.G. and Haque, M. (2021) Human Helminth Infections: A Primer. In: Humphries, D.L., Scott, M.E. and Vermund, S.H., Eds., Nutrition and Infectious Diseases, Springer, Cham, 189-215. https://doi.org/10.1007/978-3-030-56913-6 7

[40] Tefera, G. (2014) Determinants of Anemia in Pregnant Women with Emphasis on Intestinal Helminthic Infection at Sher-Ethiopia Hospital, Ziway, Southern Ethiopia. Immunology and Infectious Diseases, 2, 33-39. https://doi.org/10.13189/iid.2014.020401

[41] Hikal, W., Bratovcic, A., Baeshen, R., Tkachenko, K. and Said-Al Ahl, H. (2021) Nanobiotechnology for the Detection and Control of Waterborne Parasites. Open Journal of Ecology, 11, 203-223. https://doi.org/10.4236/oje.2021.113016

[42] Hotez, P.J., Brooker, S., et al. (2004) Hookworm Infection. New England Journal of Medicine, 351, 799-807. https://doi.org/10.1056/NEJMra032492

[43] Ibrahim, N.M. (2007) Development of an Integrated UASB-Biofilter System for Domestic Wastewater Treatment. Birzeit University, West Bank.

[44] Teklehaimanot, G.Z., Genthe, B., et al. (2015) Prevalence of Enteropathogenic Bacteria in Treated Effluents and Receiving Water Bodies and Their Potential Health Risks. Science of the Total Environment, 518-519, 441-449.

https://doi.org/10.1016/j.scitotenv.2015.03.019 